DOI 10.37882/2223-2982.2021.01-2.14

\title{
ОПТИМИЗАЦИЯ ТЕХНИЧЕСКОГО ЭЛЕМЕНТА \\ В ВОЛЕЙБОЛЕ - НАПАДАЮЩИЙ УДАР
}

\section{OPTIMIZATION OF TECHNICAL ELEMENT IN VOLLEYBALL - ATTACK}

\section{A. Rzhanov \\ O. Shishlyannikova \\ E. Matrosova \\ B. Poshvenchuk}

Summary: Forward kick (OU) is a game element that is a decoration of volleyball, which has technical features in its execution and high requirements for the players who perform it. Technical, psychological and special physical training provide criteria that contribute to the implementation of OU. The effectiveness of the attack depends on the player's motor characteristics, his skills, abilities and understanding of the psychophysical components of the whole process, which can be optimized in the training process.

The main idea and purpose of work in the correction of technical and psychomotor components of action (OU) in volleyball is the search for methods of improvement and possible specific individual qualities associated with physical characteristics and congenital inclinations.

\section{Research methods:}

Having analyzed the holistic action and disassembled it by stages of execution, into preparation, takeoff and pushing, attack, landing and switching, we will analyze and predict the criteria that are significant in performance. Step by step we will investigate the technical part associated with the biomechanical features of the movement of body segments and the combination of fusion into a common motor impulse, we will calculate energy losses and possible options for saving through the transfer coefficient from hand to ball. Let us consider the psychomotor coordination components of the discriminatory sensitivity of the parameters of their own movements, which affect individual motor functions and the overall result as a whole.

Let us experimentally prove the effectiveness of exercises that develop the selected parameters, marked by their development using tests. Let us substantiate the influence and significance of an in-depth study of complex coordination elements in sports training. Let us compare the results of the experimental and control groups, process the statistics of performance and prove the applicability of the proposed optimization methods in sports training.

\section{Research results.}

Recommendations and calculations in the correction of the attacking strike execution technique, exercises and tests that form a more accurate and effective execution, in aggregate, optimizing the full motor action, have reliability and practical significance in application.

Keywords: attacking blow, technical performance, optimization of motional action, correction of movements, volleyball, psychomotor skills.
Ржанов Алексей Александрович

Аспирант, ФГБОУВО «Иркутский начиональный исследовательский технический университет»; тренер, МБУ «Спортивная школа олимпийского резерва «АНГАРА»»,

2. Ангарск

volley-angarsk@ya.ru

Шишлянникова Ольга Алексанровна

Преподаватель, ФГБОУ ВО «Иркутский национальный исследовательский технический университет», Иркутск

Матросова Екатерина Николаевна старший преподаватель, ФГБОУ ВО «Иркутский начиональный исследовательский технический университет», Иркутск

Пошвенчук Борис Леонилович старший преподаватель, ФГБОУ ВО «Иркутский государственный медицинский университет», Иркутск

Аннотация: Нападающий удар (НУ)- игровой элемент, являющийся украшением волейбола, имеющий технические особенности в выполнении и высокие требования к игрокам, его выполняющим. Техническая, психологическая и специальная физическая подготовка обеспечивают критерии, способствующие выполнению НУ. Результативность атаки, зависит от двигательных характеристик игрока, его навыков, способностей и понимания психофизических составляющих всего процесса, которые возможно оптимизировать в тренировочном процессе.

Основная идея и цель работы в коррекции технических и психомоторных составляющих действия (НУ) в волейболе - поиск методов совершенствования и возможных специфических индивидуальных качеств, связанных с физическими особенностями и врожденными задатками.

Методы исследования: Проанализировав целостное действие и разобрав его по этапам выполнения, на подготовку, разбег и выталкивание, атаку, приземление и переключение, разберем и спрогнозируем значимые в выполнении критерии. Поэтапно исследуем техническую часть, связанную с биомеханическими особенностями движения сегментов тела и совокупность слияния в общий двигательный импульс, рассчитаем энергетические потери и возможные варианты экономии через коэффициент передачи от руки к мячу. Рассмотрим психомоторные координационные составляющие различительной чувствительности параметров собственных движений, влияющие на отдельные двигательные функции и общий результат в целом.

Экспериментальным путем докажем эффективность упражнений, развивающих выделенные параметры, маркируемые их развитие с применением тестов. 0боснуем влияние и значимость углубленного исследования сложных координационных элементов в спортивной тренировке. Сопоставим результаты экспериментальной и контрольных групп, обработаем статистику выполнения и докажем применимость в спортивной тренировке предлагаемых способов оптимизации.

Результаты исследования. Рекомендации и расчеты в коррекции техники выполнения нападающего удара, упражнения и тесты, формирующие более точное и результативное выполнение, в совокупности, оптимизирующие полное двигательное действие, имеют надежность и практическую значимость в применении.

Ключевые слова: нападающий удар, техническое выполнение, оптимизация двигательного действия, коррекция движений, волейбол, психомоторика. 


\section{Введение.}

$\mathrm{H}$ ападающий удар (НУ)- сложный и разнообразный по технике исполнения игровой элемент, для выполнения которого волейболист должен обладать кроме умения еще набором специальных физических характеристик: скоростной силы, специальной выносливости, прыгучести, ловкости или координации, а также более тонкими психомоторными способностями. (НУ) в классическом волейболе и пляжном имеет технические особенности, формирующиеся из биомеханики человека и направленны на максимально возможный результат.

\section{Шель исследования.}

Решение задачи и поиск путей оптимизации НУ, как элемента, определяющего преимущество в соревновательной деятельности.

\section{Методика и организация исследования.}

НП можно разделить на фазы выполнения для более полного и развернутого системного восприятия:

\section{1. Подготовка к атаке.}

Может иметь временной интервал от нескольких секунд до доли секунды в зависимости от игровой ситуации. Подготовка характерна своим психологическим и эмоциональным подходом, характеристикой концентрации внимания и сложной реакцией выбора. Психологический настрой может предрешать исход предстоящего игрового действия, связывает эмоциональный порыв и психические реакции с двигательным импульсом. Психомоторные реакции игрока зарождаются с мозговой активностью, подкрепляясь голосовыми функциями и позитивными исходами выработанных ранее с опытом и корректируемых сложной реакцией выбора. Концентрация внимания в данном случае ускоряет мышечное сокращение в ответ на мозговой импульс в латентном периоде передачи сенсорного сигнала.

\section{2. Разбег и выпрыгивание.}

Разбег для максимально возможного исхода атакующего действия должен содержать точное техническое исполнение, заложенное на тренировках и отработанное до исполнения на подсознании и мышечной памяти. Для исполнения атаки игроку требуется выполнить разбег, таким образом, чтоб во время замаха ударной рукой, мяч находился на наиболее удобной траектории для завершения действия. Функции, используемые человеком для точного попадания в параметры времени, пространства и усилия имеют психомоторные врожденные критерии. Сенсомоторная координация, в данном случае, интегрирована в различительной чувствительности движений и вестибулярной устойчивости.

Импульс разбега задерживается на нужный интервал времени, с использованием различительной чувствительности параметра, таким образом, чтоб старт приходился на очень короткое запаздывание, заставляющее выполнять технический элемент разбега, включающий в себя стопорящий шаг с постановкой ступни на пятку с разворотом от себя на угол 45 градусов, взмахом прямых рук и разворотом плеча ударной руки для нарастания динамики завершения атаки. Различительная пространственная чувствительность гарантирует точность дистанции параметров вытянутой руки до летящего по траектории мяча, расстояния до сетки, рук блокирующего, до боковой и лицевой отметки. Силовое различие гарантирует необходимость сокращения усилия для точного попадания или обманного действия в сторону защитников противника. Вестибулярная устойчивость и чувство равновесия используется для корректировок собственного тела в пространстве в момент выпрыгивания, где регулятором служит вторая рука, противоположная к ударной, регулирующая наклон туловища и носки стоп, натягивая на себя которые, можно увеличивать дистанцию от мяча, выдвигая тяжесть тела назад.

\section{3. Атака.}

Нанесение удара по мячу имеет так же свои технические особенности, которые игрок осваивает в период начальной подготовки. Движение ударной руки, выполняется со сложной траекторией рывкового движения локтевого сустава вверх, что ступенчато и последовательно запускает кисть, предплечье и плечо в таком порядке и на опережение. В таком случае, общее движение ударной руки по мячу напоминает удар кнутом, где каждое звено, усиливается предыдущим за счет напряжения и расслабления необходимой группы мышц в нужном порядке и в заданные временные интервалы. Действие (НУ) имеет общий импульс начала и завершения, где весь алгоритм технического и психомоторного потенциала направлен на конечную фазу атаки и результат. Движение живота и спины атакующего в заключительной фазе (НУ) продолжают движение плеча и в совокупности ко всему движению добавляют силу.

\section{4. Приземление и переключение.}

Волейбол характерен очень быстрым развитием ситуации и сменой игровой обстановки, где важным фактором является способность быстрого переключения игрока, а также скорость принятия нового решения. Приземление после атаки также имеет свои особенности. Контрольные функции игрока, после совершения атаки, определяют дальнейшее психомоторное действие, исключающее: касание сетки, переход средней линии и возможного травмирования при контакте с 
игроком противника, а также возможное продолжение игрового действия.

\section{Техника выполнения (НУ) в классическом волейболе.}

(НУ) - может иметь некоторые изменения в техническом плане, в зависимости от физических данных игрока декстрала или сенестрала, а в редких случаях и амбидекстра, так же амплуа нападающего и зоны выполнения атаки.

Классическое обучение нападающему удару начинается с разбега после определения ударной руки. Важной технической особенностью в разбеге для атаки является последний шаг перед выпрыгиванием. Он имеет самую широкую амплитуду движения и скорость по отношению к предыдущим. Разбег для атаки может иметь от одного до четырех шагов, при условии сохранения двигательного импульса с первого шага. Если после движения в сторону передачи была остановочная пауза, корректирующая точность выхода, то разбег можно считать сокращенным до одного шага, что снижает силу и высоту съема атаки. Техника выполнения последнего шага перед выпрыгиванием основана на биомеханическом соотношении инерции выталкивания после стопорящего шага. Стопа правой ноги, в случае правой ударной руки не только ставится на пятку, но и разворачивается на 45 градусов вправо, для характерного выступания левой стопы вперед на пришагивании и развороте корпуса вправо, для выдвигания назад правого плеча. Толчок с противоположной для ударной руки ногой не имеет никаких преимуществ в двигательном акте атаки, выглядит несуразно и характеризует несостоятельность первого тренера, имеющего отношение к подготовке. Каждое движение в техническом плане имеет закономерность с критерием, ведущим к более точному и качественному результату и должно отражать совокупность элементов, сокращающих или увеличивающих амплитуду движения в зависимости от задачи.

\section{Технические особенности сенестрала (левши).}

Атакующий левша - всегда огромный плюс в команде, при условии качественной подготовки. Левая атакующая рука в амплуа связующего имеет особое преимущество. К сожалению, амплуа связующего имеет очень высокие критерии в спортивном отборе, и далеко не каждый игрок-левша способен обеспечивать игровые потребности. Показывая передачу в прыжке и заставляя противника отвлекаться на блокирующее действие, связующий самостоятельно принимает решение атаковать или выполнять передачу. Позитивная особенность такой атаки в непредсказуемости, а минусы в слабой амплитуде и невозможности изменить угол перевода.
Удобным для выхода в точку атаки, так же является амплуа диагонального игрока левши, что используется повсеместно. Второй и первый номер для атакующего левши зеркально повторяет работу доигровщика правши в техническом исполнении, но и имеет более не предсказуемый угол атаки для блокирующих.

\section{Технические особенности амбидекстра.}

Уникальность таких игроков очевидна и встречаются они, с учетом избранного вида спорта, крайне редко. Знание особенностей психологии амбидекстров поможет в формировании технических особенностей в обучении. Решающим фактором должна быть сложная реакция выбора игрока и одинаково отработанная техника разбега на две стороны. Предпочтение руки для атаки игрок выберет самостоятельно, не только по ему понятным критериям, но и в тактическом плане.

\section{Техническая особенность атаки в плялжном волейболе.}

Техническая особенность (НУ) в пляжном волейболе имеется, в связи с мягкостью покрытия, а также с невозможностью использовать динамику разбега и стопорящего шага с сохранением импульса и, тем более, его нарастания. В связи с этой особенностью в пляжном волейболе акцент и вся техническая часть (НУ) приходится на выталкивание уже практически с места, а весь разбег состоит из удобного подхода к коридору для атаки. Психомоторная деятельность в атаке волейболистов- пляжников больше направленна на концентрацию внимания и сложную реакцию выбора, которая помогает принимать решения, относительно тактических маневров противника на блоке и в защите. Такая атака нуждается в еще большей динамике выноса прямых рук, отведённых на взмахе до конца с наклоном корпуса для увеличения амплитуды и еще большего сгибания ног в коленном суставе, что несколько компенсирует отсутствие возможности направления ускорения разбега в выпрыгивании.

\section{Эксперимент.}

Техническая сторона (НУ) имеет ранний сенситивный период и отрабатывается на начальной подготовке путем имитационных и подводящих упражнений. Психологическая сторона, имеет накопительную составляющую, которая дополняет и корректирует врожденный потенциал спортсмена, его темперамент. Изучив психомоторную составляющую (НУ), как двигательное действие, состоящее из четырех основных фаз, можно допустить, что оптимизацию и совершенствование всего процесса следует осуществлять по параметрам:

- Концентрации внимания и сложной реакции выбора

- Вестибулярной устойчивости и равновесия 
Упражнения для совершенствования исполнения (НП).

\begin{tabular}{|c|c|c|c|}
\hline № & Упражнение с описанием & Двигательная способность & Дополнительное оборудование \\
\hline 1 & $\begin{array}{l}\text { Циклические повторения перемещений, } \\
\text { статодинамических прыжков, с имитацией } \\
\text { разбега, взмаха руками. }\end{array}$ & Сенсорная координация & $\begin{array}{l}\text { Координационная лестница, барьеры, пира- } \\
\text { мидки, теннисные мячи для имитации }\end{array}$ \\
\hline 2 & $\begin{array}{l}\text { Атака с разбега: по статическому тренажеру } \\
\text { с мячом, с собственного наброса, с наброса } \\
\text { напарника с элементами акробатики (кувы- } \\
\text { рок, разворот на } 360 \text { градусов) }\end{array}$ & $\begin{array}{l}\text { РЧД, вестибулярная устойчивость, равно- } \\
\text { весие, внимание и концентрация. }\end{array}$ & $\begin{array}{l}\text { Тренажер для атаки, маты для кувырков, } \\
\text { игровые мячи. }\end{array}$ \\
\hline 3 & $\begin{array}{l}\text { удар стоя и в движении вытянутой рукой } \\
\text { без прыжка, после высокого выбрасывания } \\
\text { ударной рукой мяча вертикально по мячу } \\
\text { вверх (на точность, на технику выполнения, } \\
\text { на скорость) }\end{array}$ & $\begin{array}{l}\text { РЧД (различие по времени, пространству, } \\
\text { усилию) }\end{array}$ & Игровые мячи \\
\hline 4 & $\begin{array}{l}\text { Выполнение (НУ) с привязью на резине для } \\
\text { скоростно- силового развития с вариантами } \\
\text { психомоторных усложняющих элементов: } \\
\text { кувырок, выпрыгивание, задержка дыхания } \\
\text { на вдохе или выдохе) }\end{array}$ & $\begin{array}{l}\text { РЧД, вестибулярная устойчивость, равно- } \\
\text { весие, концентрация внимания, волевые } \\
\text { качества, специальная выносливость. }\end{array}$ & $\begin{array}{l}\text { Координационная лестница, скакалки, маты } \\
\text { для кувырков, игровые мячи. }\end{array}$ \\
\hline 5 & $\begin{array}{l}\text { Выполнение атаки на высоту съема через } \\
\text { блок с переключением на звуковой сигнал. } \\
\text { Первый сигнал к выполнению, второй для } \\
\text { выбора дальнейшего исхода (один короткий } \\
\text { свисток-выполнить атаку с переводом в } \\
\text { лево, два коротких- в право, без сигнала } \\
\text { скидка за блок и т.д. вариации. }\end{array}$ & $\begin{array}{l}\text { Сложная реакция выбора, РЧД (различи- } \\
\text { тельная силовая чувствительность по трем } \\
\text { параметрам) }\end{array}$ & $\begin{array}{l}\text { Игровые мячи, тренажёр для блока или } \\
\text { скамью для блокирующих. }\end{array}$ \\
\hline
\end{tabular}

\section{- Различительной чувствительности движения по параметрам}

Для подтверждения гипотезы, проведем эксперимент, с сентября 2019 по сентябрь 2020 года поделим юношей количеством 30 человек, начальной подготовки спортивных школ города Ангарска возрастом 10-12 лет, на экспериментальную и контрольную группы. Для однородности подготовки, проведем тестирование по указанным параметрам, далее с согласия детей и их родителей, подвергнем экспериментальную группу тренировочным развивающим упражнениям, состоящим на наш взгляд из компонентов, способствующих развитию психомоторные параметры составляющими двигательное действие (НУ). Тренировочная нагрузка состоит из пяти упражнений, имеющих различные варианты и общей рассчитанной годовой нагрузкой 192 часа. Контрольная группа будет тренироваться в обычном режиме, а в завершении эксперимента, обе группы будут протестированы по вводному тесту повторно. Для достоверности эксперимента, проведем статистический анализ атакующего действия игроков контрольной и экспериментальной групп в соревновательном процес- се между собой.

Тестирование пространственного различия (А) проведем прибором «курвиметр», который повторяет траекторию и точно определяет ее размер. Игроку предлагается нарисовать кривую линию с точно заданным размером - пять сантиметров, а прибор служит для определения попадания в параметр.

Тестирование чувствительности малых временных интервалов (Б), проведем секундомером, по заданию, остановить секундомер через 15 секунд.

Чувствительность по усилию (В) протестируем «кистевым динамометром». После создания максимального усилия (100\%), предложим без зрительного контроля шкалы создать усилие 70\%, попадание в параметр послужит результатом.

Используя тесты, как маркер в оптимизации психомоторных составляющих (НУ), спортсменов экспериментальной группы в течении года будем подвергать тренировочному воздействию (таблица 1). 
Результаты исследования и их обсужление.

Таблица 2

Результаты эксперимента.

\begin{tabular}{|l|c|c|c|c|}
\multirow{2}{*}{\multicolumn{2}{|c|}{ тест }} & \multicolumn{2}{|c|}{ Экспериментальная группа } & \multicolumn{2}{|c|}{ Контрольная группа } \\
\cline { 2 - 5 } \cline { 2 - 5 } & Начало (\%) & Конец (\%) & Начало (\%) & Конец (\%) \\
\hline А & 68,72 & 88,17 & 64,41 & 67,22 \\
\hline Б & 66,82 & 94,16 & 66,78 & 68,32 \\
\hline В & 73,42 & 96,18 & 69,39 & 74,67 \\
\hline
\end{tabular}

В результате исследования и его анализа, можно констатировать позитивное изменение по всем параметрам. Изменения в экспериментальной группе по отно- шению к собственным результатам в тесте (A) составили $19,45 \%$, в тесте (Б) 27,34\%, в тесте (В) 22,76\%. По отношению к финальному результату контрольной группы в тесте (А) 20,95\%, в тесте (Б) 25,84\% в тесте (В) 21,51\%. Таким образом общее среднее изменение результата экспериментальной группы к контрольной по всем параметрам составила 22,76\%, а собственный результат вырос на $23,18 \%$.

В первом этапе, разобрав на составляющие психомоторные двигательные реакции и развивая их, получаем позитивный сдвиг по всем параметрам. Вторым этапом сравним статистику реализации атак, после воздействия на тонкие двигательные параметры экспериментальной

Таблица 3

Общая статистика атак по партиям.

\begin{tabular}{|c|c|c|c|c|c|c|c|c|c|c|c|}
\hline \multicolumn{9}{|c|}{ Экспериментальная группа } & \multicolumn{1}{|c|}{ Контрольная группа } \\
\hline № & 1 & 2 & 3 & 4 & $\Sigma$ & № & 1 & 2 & 3 & 4 & $\Sigma$ \\
\hline 1 & $3-2$ & $0-1$ & $2-0$ & $0-0$ & $5-2$ & 1 & $0-1$ & $0-0$ & $2-0$ & $0-0$ & $2-1$ \\
\hline 2 & $2-1$ & $0-1$ & $0-0$ & $2-0$ & $4-1$ & 2 & $0-1$ & $0-1$ & $0-0$ & $0-0$ & $0-2$ \\
\hline 3 & $2-2$ & $2-1$ & $0-1$ & $2-2$ & $6-6$ & 3 & $0-0$ & $0-0$ & $0-0$ & $0-1$ & $0-1$ \\
\hline 4 & $2-1$ & $2-1$ & $0-1$ & $0-1$ & $4-4$ & 4 & $0-0$ & $0-1$ & $0-0$ & $2-0$ & $2-1$ \\
\hline 5 & $2-1$ & $0-1$ & $2-0$ & $0-0$ & $4-1$ & 5 & $0-0$ & $0-0$ & $0-1$ & $0-0$ & $0-1$ \\
\hline 6 & $0-1$ & $2-1$ & $2-2$ & $0-0$ & $4-3$ & 6 & $0-0$ & $0-0$ & $0-0$ & $0-1$ & $0-1$ \\
\hline 7 & $2-0$ & $0-1$ & $0-0$ & $0-1$ & $2-2$ & 7 & $0-0$ & $0-0$ & $0-0$ & $2-0$ & $2-0$ \\
\hline 8 & $0-1$ & $2-1$ & $0-1$ & $2-0$ & $4-2$ & 8 & $0-0$ & $0-1$ & $0-0$ & $0-1$ & $0-2$ \\
\hline 9 & $0-0$ & $2-1$ & $2-0$ & $0-1$ & $4-2$ & 9 & $0-0$ & $0-0$ & $0-0$ & $0-1$ & $0-1$ \\
\hline 10 & $3-0$ & $0-1$ & $2-2$ & $0-1$ & $5-3$ & 10 & $0-1$ & $2-0$ & $0-0$ & $2-1$ & $4-2$ \\
\hline 11 & $3-2$ & $2-2$ & $2-0$ & $3-1$ & $7-5$ & 11 & $0-0$ & $0-0$ & $0-0$ & $0-0$ & $0-0$ \\
\hline 12 & $0-1$ & $3-2$ & $1-0$ & $0-1$ & $4-4$ & 12 & $0-0$ & $0-1$ & $0-0$ & $0-0$ & $0-1$ \\
\hline 13 & $1-0$ & $0-1$ & $2-2$ & $0-1$ & $3-4$ & 13 & $0-1$ & $2-0$ & $0-0$ & $2-1$ & $4-2$ \\
\hline 14 & $1-2$ & $2-2$ & $2-0$ & $1-1$ & $6-5$ & 14 & $0-0$ & $0-0$ & $0-0$ & $0-0$ & $0-0$ \\
\hline 15 & $0-1$ & $3-2$ & $2-0$ & $0-0$ & $5-2$ & 15 & $0-0$ & $0-1$ & $0-0$ & $0-0$ & $0-1$ \\
\hline $567-48, \mathrm{t}=5,42$ & & & & & $514-16, \mathrm{t}=2,16$ & & \\
\hline
\end{tabular}

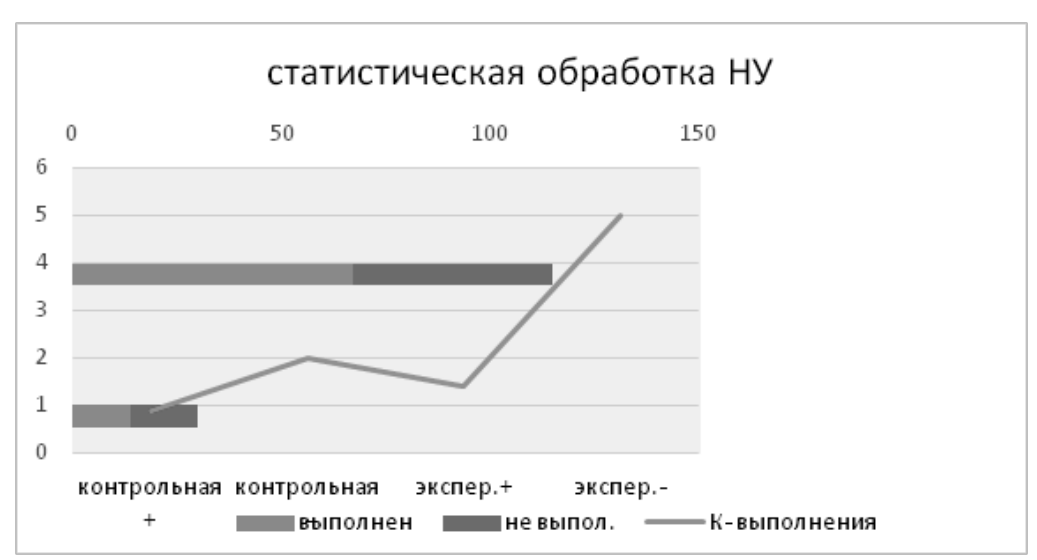

Рис. 1. Выполнение атаки после эксперимента 
группы с контрольной. Статистика указывается в двух значениях, реализованная атака и не реализованная, выполненная с ошибкой или не доведенная до логического конца. Игровой эксперимент состоялся со счетом 3:1 в пользу экспериментальной группы, статистика велась четыре партии (таблица 3).

Сравним t-критерий: 5,42>2,16, что говорит о преимуществе эксперимента и подтверждает достоверность результатов.

\section{Энергетические затраты в прочессе выполнения (HУ).}

Техническое выполнение удара по мячу закономерно связанно с экономией затрат энергии и максимальной отдачей используемой амплитуды целостного движения сегментов руки, где потеря энергии зависит от биомеханики контактирующих звеньев. Количественное значение потерь энергии, можно выразить через формулу коэффициента восстановления (К1):

\begin{tabular}{|c|c|c|}
\hline $\begin{array}{l}\text { К1 = } \frac{\text { В1 - В2 }}{\text { C1 - С2 }} \\
\text { (С) ударная скорость } \\
\text { руки, (В) - ударная } \\
\text { скорость мяча. }\end{array}$ & $\begin{array}{l}\text { К2 = А после + Апосле } \\
\text { Адо + Адо } \\
\text { (А) - кинетическая } \\
\text { энергия руки и мяча до } \\
\text { и после удара. }\end{array}$ & $\begin{array}{l}\text { К2 }=(1-\mathrm{K} 2)^{2} \frac{\mathrm{N} 1-\mathrm{N} 2}{\mathrm{~N} 1+\mathrm{N} 2} \\
\text { для удара К2=1 } \\
\text { абсолютно упругих тел } \\
\text { с сосредоточенными } \\
\text { массами и (с учетом } \\
\text { что K2=1, a =0) }\end{array}$ \\
\hline
\end{tabular}

Для энергетической оценки, вводим коэффициент потерь как соотношение потерянной энергии к начальной через восстановление.

Чем выше К2, тем меньше рассеивание энергии в ударной системе, что и необходимо для сообщения большой скорости вылета мячу при (НУ). Для расчета ударного движения имеет значение коэффициент передачи энергии, от показателя кинетической энергии, по- терянной в результате выполнения ударного действия. Следовательно, коэффициент передачи энергии от руки к мячу будет увеличиваться с увеличением затрачиваемой в ударе кинетической энергии или жесткая ударная кинематическая система полнее передает механическую энергию ударяемому мячу.

\section{ЗакАючение.}

Совершенствование технической части выполнения нападающего удара результативно производить через психомоторные составляющие общего двигательного действия. Сложнокоординационные элементы более точно поддаются выполнению и корректировкам через различие тонко-дифференцированных ощущений и восприятий собственных движений по параметрам. Совокупность концентрации внимания и знания собственных возможностей позволяет игроку развивать врожденные психомоторные задатки и использовать скрытый потенциал в спортивной деятельности.

\section{Выводы.}

1. Оптимизацию сложного двигательного действия можно проводить через разбор биомеханики и коррекции техники выполнения, рассчитав места возможных энергетических потерь.

2. Упражнения, подобранные для развития психомоторных составляющих общего двигательного психомоторного акта, набор тестов маркирующий развитие и изменение в освоении составляющих элементов имеет достоверное позитивное значение прироста по параметрам и статистически доказывает общий результат тренировочного воздействия.

3. Спортивная тренировка может представлять более продуктивный процесс, через расстановку технических и психомоторных элементов в совокупности с индивидуальными физическими и психическими показателями спортсменов.

\section{ЛИТЕРАТУРА}

1. Германов, Н.Г. Формирование оперативного мышления у юных волейболистов 13-15 лет в условиях интерактивного решения игровых задач [Текст] /Г.Н. Германов, Д.А. Черный, В.Д. Мачульская // Ученые записки университета им. П.Ф. Лесгафта. 2017. - № 5 (147). - С. 26-30.

2. Мезенцев, В.В. Оценка показателей психомоторных способностей юных хоккеистов с мячом в годичном учебно-тренировочном цикле. /Ученые записки университета имени П.Ф. Лесгафта. - 2017. - № 2 (144).

3. Новожилова, С.В. Оценка соревновательных нагрузок у волейболистов [Текст] / С.В. Новожилова, Е.В. Игнатова, С.Н. Авдеева // Вестник Костромск. гос. ун-та. Серия: Педагогика. Психология. Социокинетика. - 2017. - Т. 23. -№ 1. - С. 86-88.

4. Ржанов, А.А., Психомоторный-латентный период и развитие внимания, как элемента, влияющего на общие психомоторные показатели волейболиста / А.А. Ржанов, А.И. Несмеянов, Е.Н. Матросова // Современная наука: актуальные проблемы теории и практики. Серия «Гуманитарные науки». -2020. -№04. -C. 86-88 D0I 10.37882/2223-2982.2020.04.25

5. Ржанов, А.А. Методика развития психомоторных компонентов ловкости юных волейболистов / А.А. Ржанов //Научный журнал «Вестник КГПУ им. В.П. Астафьева». 2020. № 3 (53). D0l: https://doi.org/10.25146/1995-0861-2020-53-3-235

6. Ржанов, А.А. Методика развития координационной выносливости в волейболе / А.А. Ржанов, О.А. Швачун, О.А. Шишлянникова, Э.Б. Бальжинимаев, Н.В. 
Сметанина-Куршевски // Ученые записки университета имени П.Ф. Лесгафта. -2020-№ 10(188) c. 304-309. DOI: 10.34835/issn.2308-1961.10.p304-309

7. Шелков, М.В. Влияние гипоксической тренировки на показатели гомеостаза у конькобежцев в подготовительном периоде / М.В. Шелков, Ф.А. Щербинина, М.B. Баканов // International Journal of Humanities and Natural Sciences, vol.7-1 Международный журнал гуманитарных и естественных наук 2019г. C. 84- 86 // D0I:10.24411/2500-1000-2019-11375

(c) Ржанов Алексей Александрович (volley-angarsk@ya.ru), Шишлянникова Ольга Алексанровна, Матросова Екатерина Николаевна, Пошвенчук Борис Леонилович

Журнал «Современная наука: актуальные проблемы теории и практики»

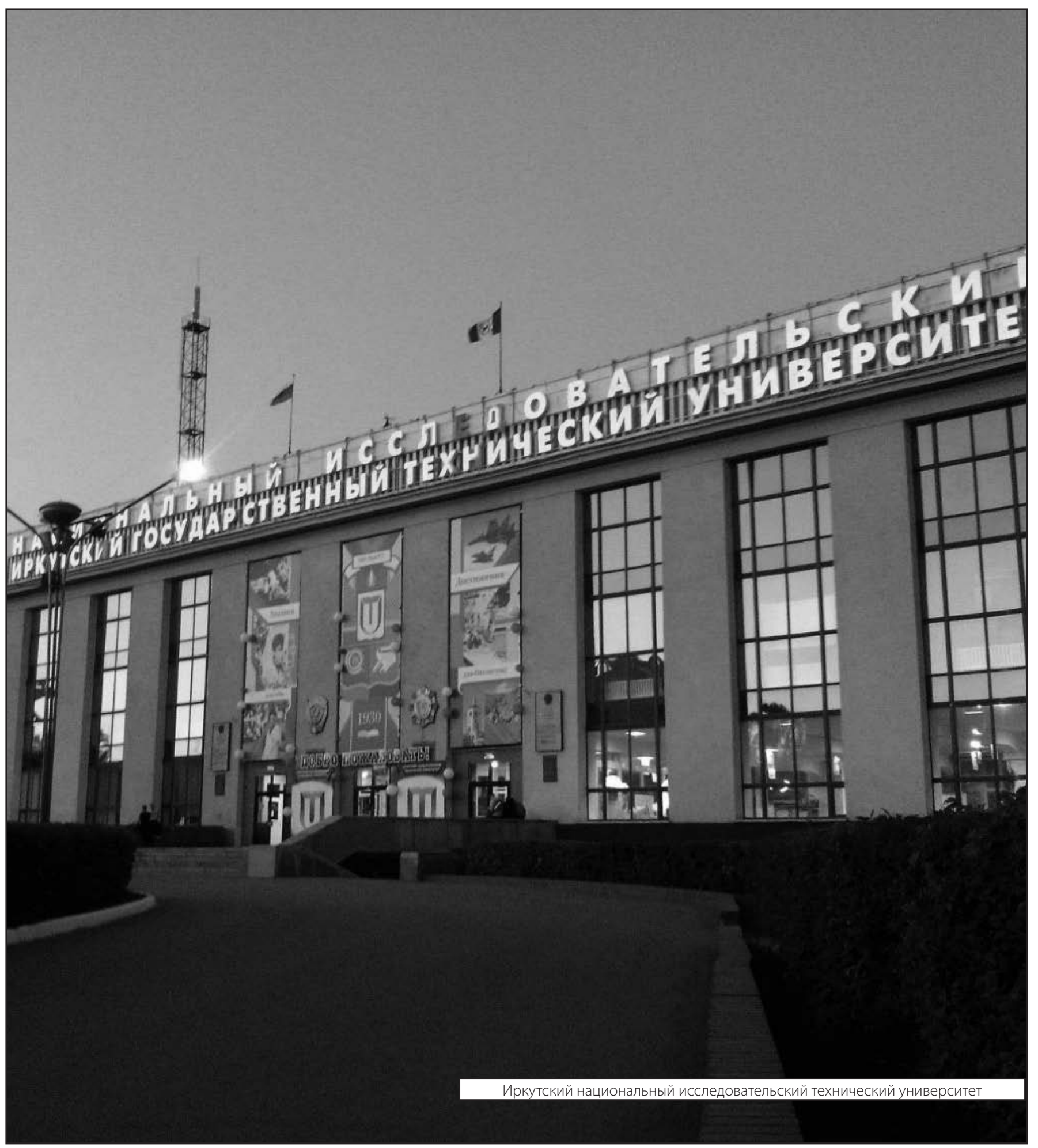

